\title{
Patient and Healthcare Provider Perspectives of First- Generation Somatostatin Analogs in the Management of Neuroendocrine Tumors and Acromegaly: A Systematic Literature Review
}

\author{
David Cella · Jennifer Evans · Marion Feuilly · Sebastian Neggers • \\ Dirk Van Genechten · Jackie Herman · Mohid S. Khan
}

Received: October 22, 2020 / Accepted: December 5, 2020 / Published online: January 11, 2021

(c) The Author(s) 2021

\begin{abstract}
Introduction: Somatostatin analogs (SSAs) are used to treat neuroendocrine tumors (NETs) and acromegaly. Two first-generation SSAs, octreotide long-acting release (OCT LAR) and lanreotide autogel/depot (LAN), are available. A systematic literature review (SLR) was conducted to investigate which characteristics beyond efficacy are most important in patient and healthcare practitioner (HCP) experience of
\end{abstract}

Marion Feuilly was an employee of Ipsen at the time of these analyses.

Supplementary Information The online version contains supplementary material available at https:// doi.org/10.1007/s12325-020-01600-x.

D. Cella $(\bowtie)$

Department of Medical Social Sciences,

Northwestern University Feinberg School of

Medicine, Chicago, IL, USA

e-mail: d-cella@northwestern.edu

J. Evans

Costello Medical, Cambridge, UK

M. Feuilly

Ipsen Pharma, Boulogne Billancourt, France

S. Neggers

Department of Medicine, Section Endocrinology,

Erasmus University Medical Center, Rotterdam, The

Netherlands
LAN and OCT when used to treat acromegaly and NETs.

Methods: MEDLINE, Embase, the Cochrane Library, and Database of Abstracts of Reviews of Effect were searched from database inception to January 2019 with terms for first-generation SSAs, NETs, acromegaly, preferences, decisionmaking, and human factors. Key congresses in 2016-2018 and SLR bibliographies were handsearched. Two independent reviewers screened articles at title/abstract and full-text stage. Publications fulfilling pre-specified inclusion criteria reported patient or HCP perspectives of LAN or OCT, or any factors affecting treatment perspectives for NETs or acromegaly.

Results: A total of 1110 unique records were screened, of which 21 studies were included, reporting from the perspectives of patients $(n=18)$ and/or HCPs $(n=9)$. Perspectives were

\section{Van Genechten}

Belgian Neuroendocrine Tumour (NET) and

Multiple Endocrine Neoplasia (MEN) Association,

Blankenberge, Belgium

D. Van Genechten

International Neuroendocrine Cancer Alliance

(INCA), Boston, MA, USA

\section{J. Herman}

Canadian Neuroendocrine Tumour Society,

Cornwall, ON, Canada

M. S. Khan

University Hospital of Wales, Cardiff, UK 
collected using shared decision-making frameworks, questionnaires, informal patient opinion, and a Delphi panel. Where patient preference was specifically reported, LAN was preferred in $4 / 5$ studies and OCT LAR in $1 / 5$. Common factors underlying treatment experience included technical problems with injections and associated pain, emotional quality/ anxiety of injections, time and convenience of treatment administration, and independence. Immediate aspects of injections appeared most important to patients, though the possibilities of extended dosing intervals and self-/partnerinjection with LAN were also notable factors.

Conclusions: Study outcomes favored LAN in this SLR, with factors surrounding injection administration most influential in treatment experience. The findings of this SLR provide a basis that could inform development of decision-making criteria, with patient and HCP treatment perspectives considered. Future studies should utilize a common method to report preference and associated drivers.

Keywords: Acromegaly; Neuroendocrine tumors; Preference; Somatostatin analogs; Treatment perspectives

\section{Key Summary Points}

Why carry out this study?

This manuscript reports the findings of a systematic literature review (SLR) to investigate which characteristics of firstgeneration somatostatin analogs (SSAs), beyond efficacy, are most important from patient and healthcare practitioner (HCP) perspectives, when used to treat acromegaly and neuroendocrine tumors.

\section{What was learned from the study?}

A total of 26 publications reporting on 21 studies were included in this SLR, reporting from the perspectives of patients $(n=18)$ and HCPs $(n=9)$, using shared decision-making frameworks, questionnaires, informal patient opinion, and a Delphi panel.
Common factors underlying treatment experience with long-acting lanreotide and octreotide included technical problems with injections and associated pain, emotional quality/anxiety of injections, time and convenience of treatment administration, and patient independence; immediate aspects of injection administration appeared most important to patients.

Where study participants had direct experience of both SSAs, four of the five studies reporting patient preference, and the only study reporting preference of HCPs, reported preference for lanreotide autogel over octreotide long-acting release.

\section{DIGITAL FEATURES}

This article is published with digital features, including a summary slide, to facilitate understanding of the article. To view digital features for this article go to https://doi.org/10.6084/ m9.figshare.13333565.

\section{INTRODUCTION}

Long-acting somatostatin analogs (SSAs) are used to treat neuroendocrine tumors (NETs) with and without features of carcinoid syndrome (CS), the latter resulting from the hypersecretion of serotonin and other vasoactive substances from NETs [1-3]. The European Neuroendocrine Tumor Society (ENETS) and National Comprehensive Cancer Network (NCCN) guidelines recommend SSAs as first-line systemic therapy for unresectable and/or metastatic gastroenteropancreatic neuroendocrine tumors (GEP-NETs) following surgery [4, 5]. SSAs are also indicated as primary and adjuvant treatment for acromegaly, a disorder resulting from the overproduction of growth hormone from adenomas, for patients who are unable to undergo surgery, are not cured by surgery, or otherwise require medical treatment [6-8]. The 
clinical efficacy and safety of the two first-generation SSAs lanreotide autogel/depot (LAN) and octreotide long-acting release (OCT LAR) has been previously demonstrated; both SSAs have been shown to decrease growth hormone and insulin-like growth factor 1 levels in patients with acromegaly [9-13], as well as to contribute to progression-free survival in patients with NETs [14-19].

LAN is approved in countries including Europe and the USA for long-term treatment of acromegaly, treatment of gastrointestinal (GI) NETs and pancreatic NETs, and of symptoms associated with NETs (EU only) $[8,18]$. In Europe, LAN is also indicated for NETs of unknown origin and NETs with a Ki-67 index of up to $10 \%$ [8]. LAN is supplied in a pre-filled syringe, administered by deep subcutaneous injection once every 4 weeks [20, 21]. Additionally, extended dosing intervals (EDIs) are available for patients with acromegaly when symptom control is stable [18], and this ready-to-use formulation allows for the possibility of self-injection by patients with NETs and acromegaly in most geographies (self-injection not yet approved in the USA) $[8,18]$.

OCT LAR is indicated for long-term treatment of acromegaly in Europe and the USA $[19,22]$. OCT LAR is also approved in Europe for symptom and tumor control in GI NETs or NETs of unknown primary origin, and in the USA it is approved for the treatment of symptoms in metastatic carcinoid tumors [19, 22]. A shortacting OCT daily subcutaneous injection formulation was previously used in long-term treatment of acromegaly and GEP-NETs [23], though this is now mainly used for prophylaxis of carcinoid crises prior to surgeries, or as rescue treatment in the case of acute symptoms. OCT LAR is provided as a powder that requires reconstitution in a solvent by a healthcare practitioner (HCP) before intramuscular injection $[19,22]$.

Despite their therapeutic benefits and wide use in clinical practice over the last two decades, understanding of which SSA product characteristics beyond efficacy and safety impact the treatment experience of patients and HCPs is currently limited. The objective of this SLR was to identify treatment characteristics that influence patient and HCP experience of LAN and OCT LAR when used to treat acromegaly and NETs. As such, this SLR sought to determine distinguishing factors between the two SSAs that could be considered in treatment decisionmaking.

\section{METHODS}

\section{Search Strategy}

Databases including MEDLINE, Embase, the Cochrane Database of Systematic Reviews, the Database of Abstracts of Reviews of Effect, and the Cochrane Central Register of Controlled Trials were searched from database inception to 11 January 2019 using terms for SSAs, NETs or acromegaly, preferences, decision-making, and human factors (a full list of search terms can be found in Tables S1-S4). Terms were decided through consultation with independent experts in SLR design and development. Congresses that had taken place in 2016-2018 including the North American Neuroendocrine Tumor Society, European Neuroendocrine Tumour Society, European Congress of Endocrinology, Pituitary Society International Congress, and UK and Ireland Neuroendocrine Tumour Society were hand-searched for further evidence using the search terms based on those used in the electronic databases, and strategies were based on the search functions of the individual conferences. Bibliographies of relevant SLRs were also hand-searched.

\section{Study Selection and Data Extraction}

Abstracts and full texts eligible for inclusion in this SLR must have been published in English and reported data pertaining to adult patients with NETs or acromegaly receiving treatment with long-acting formulations of LAN or OCT, or to their HCPs. Studies reported information regarding treatment experience or SSA preference, including but not limited to opinion of safety, efficacy, direct costs; indirect costs; nonutility quantitative measures; and qualitative findings in interviews or focus groups. Full 
eligibility criteria are detailed in Table S5. Two independent reviewers screened records for inclusion using the pre-specified criteria at the title/abstract stage and full-text stage, and any discrepancies were resolved by discussion until a consensus was met. If necessary, a third reviewer made the final decision. Where the applicability of the inclusion criteria was unclear, articles were included at the abstract stage to ensure that all potentially relevant studies were captured. Articles of unclear relevance could then be excluded at the full-text stage to ensure that only relevant articles were ultimately included. Relevant data pertaining to study design, location, date and duration, treatment arms, funding, study aims and eligibility criteria, interventions, and results from the included studies were extracted into prespecified Microsoft Word extraction grids.

\section{Quality Assessment}

The quality of the included studies was assessed using the Purpose, Respondents, Explanation, Findings, Significance (PREFS) checklist, a tool specifically designed to assess the quality of preference studies [24]. The quality of each study was assessed by a single individual, with the conclusions regarding quality confirmed independently by a second individual; any discrepancies were discussed, and final decisions were made by a third individual where necessary.

\section{Compliance with Ethics Guidelines}

This article is based on previously conducted studies and does not contain any new studies with human participants or animals performed by any of the authors.

\section{RESULTS}

\section{Study Selection}

A total of 1110 records from database searches and 990 records from congresses and SLR bibliographies were screened. In total, 26 publications reporting on 21 unique studies were included in this SLR (Fig. 1).

\section{Study Characteristics}

Of the 21 included studies, 10 reported on the treatment of NETs [25-33], 10 reported the treatment of acromegaly [34-43], and one reported both [44]. The included studies were conducted using a range of study designs, most commonly including open-label trials $[25,27,34,37]$, and prospective observational studies [25, 31, 39, 43] among others (Table 1). Group comparison studies compared experience between patients on parallel treatment arms $[25,26,28,29,31,32,36,41-44]$ whereas crossover studies reported the experience of patients who switched from one SSA to the other $[34,35,37,38,40]$. Patients switched from OCT LAR to LAN treatment in all crossover studies. Most studies $(n=19)$ were conducted in the USA and/or Europe (Table 1).

All but one of the studies included LAN [25-44]; 17 compared LAN with OCT $[25,26,28,29,31-38,40-42,44]$, four studies investigated different formulations or administration methods of LAN exclusively [30, 33, 39, 43], and a single study exclusively investigated different formulations of OCT [27]. Most studies did not specifically aim to investigate patient or HCP perspectives of SSA treatments; efficacy and tolerability of treatment were often the primary outcomes in these cases, and treatment perspective was collected as a secondary or exploratory outcome. The majority of studies $(n=12)$ used structured questionnaires or surveys to elicit patient or HCP treatment perspectives or preference $[25,26,28,30,31,36,38-41,43,44]$, though these were not validated instruments, and informal patient questioning was also a common approach $(n=5)$ [27, 34, 35, 37, 42]. Methods less frequently employed included use of a patient-clinician shared decision-making framework [29, 33], and a Delphi panel [32]. As such, where preference was not explicitly reported, the independent investigators reviewing the studies in this SLR assessed the statistical and numerical comparisons presented 


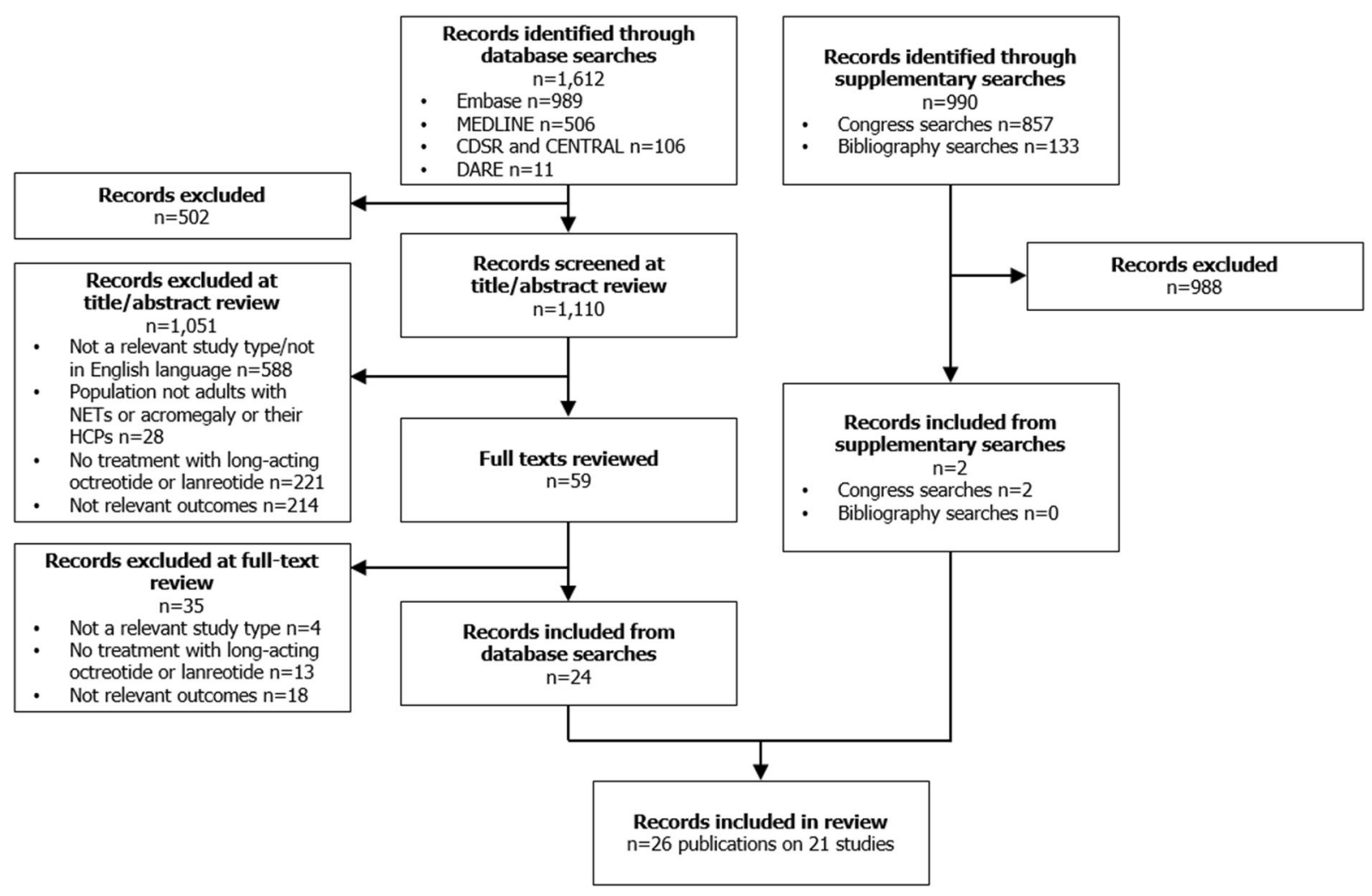

Fig. 1 PRISMA diagram for included studies. CDSR Cochrane Database of Systematic Reviews, CENTRAL Cochrane Central Register of Controlled Trials, DARE Database of Abstracts of Reviews of Effects, HCPs

in each study. These comparisons were used to determine which, if any, of the two treatments was associated with the more favorable outcome, such as lowest level of anxiety or fewest technical problems, for example. Including preference, nine key outcomes in treatment experience were identified (Table 2). Here, we focus on studies in which respondents had direct experience of SSA treatment (rather than anticipated preference) and where statistical or numerical comparisons were provided (rather than qualitative comparisons).

\section{Treatment-Specific Preference}

Of the 21 studies included in this SLR, five crossover studies explicitly reported the preferences of patients who had direct experience of both LAN and OCT LAR treatment (Table 3) healthcare practitioners, NETs neuroendocrine tumors, PRISMA Preferred Reporting Items for Systematic Reviews and Meta-Analyses

$[34,35,37,39,40]$. LAN was preferred in four of the five studies that reported patient preference as an outcome [34, 37, 39, 40]. All crossover studies included patients who switched from OCT LAR to LAN with the standard 28-day dosing interval for each treatment.

Salvatori et al. reported that $81.3 \%$ of patients preferred LAN in comparison with $12.5 \%$ for OCT LAR $(n=33, p=0.0001)$, based on a structured questionnaire, though reasons for preference were not reported [38]. Alexopoulou et al. reported that 17/25 (68\%) patients with acromegaly chose LAN by informal opinion, whereas $2 / 25$ (8\%) preferred OCT LAR; 6/25 (24\%) patients did not report treatment preference [34]. Reduced pain at the injection site and fewer technical problems following LAN injection were deemed by investigators in this study to influence patient choice [34]. 


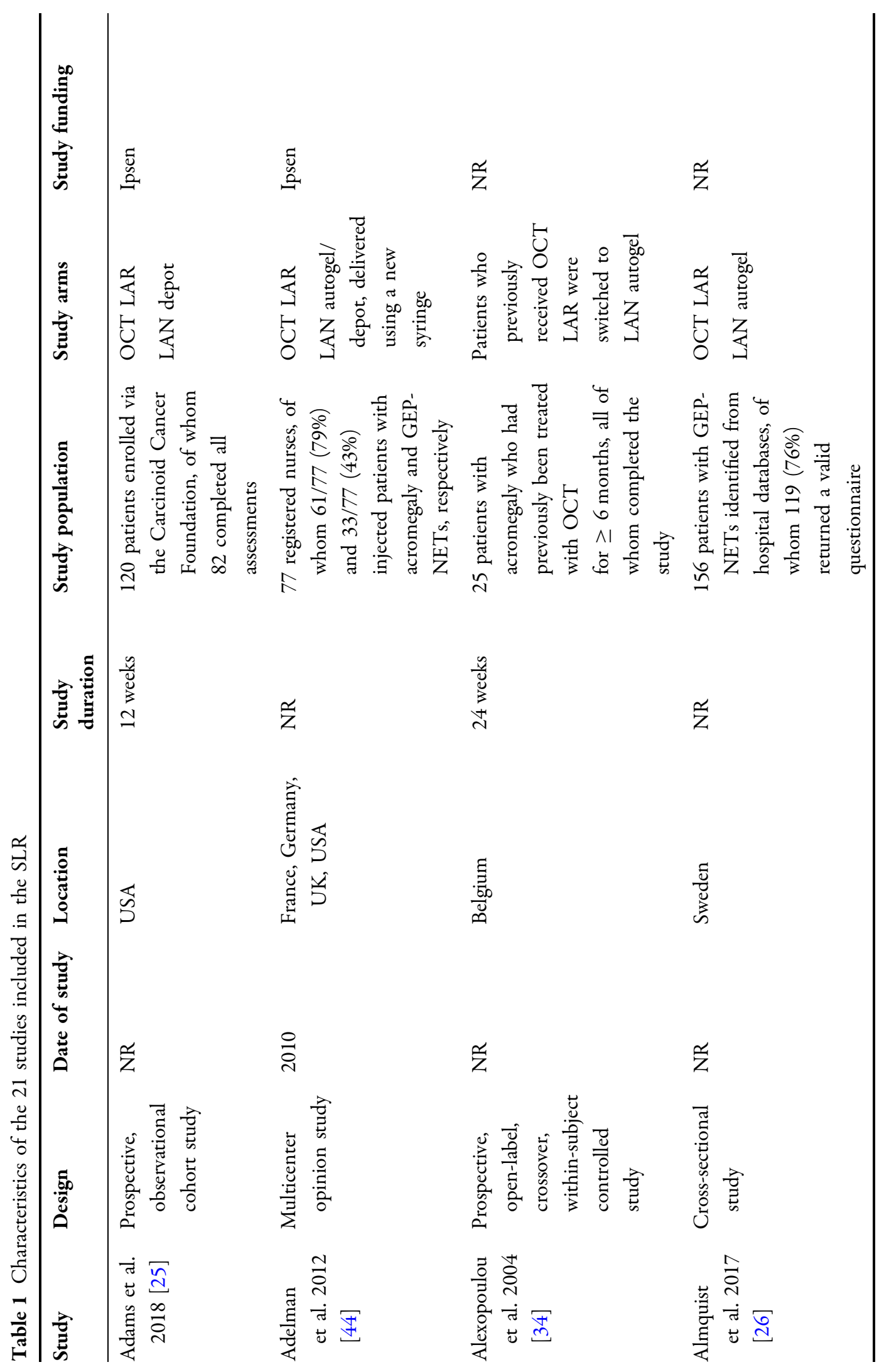




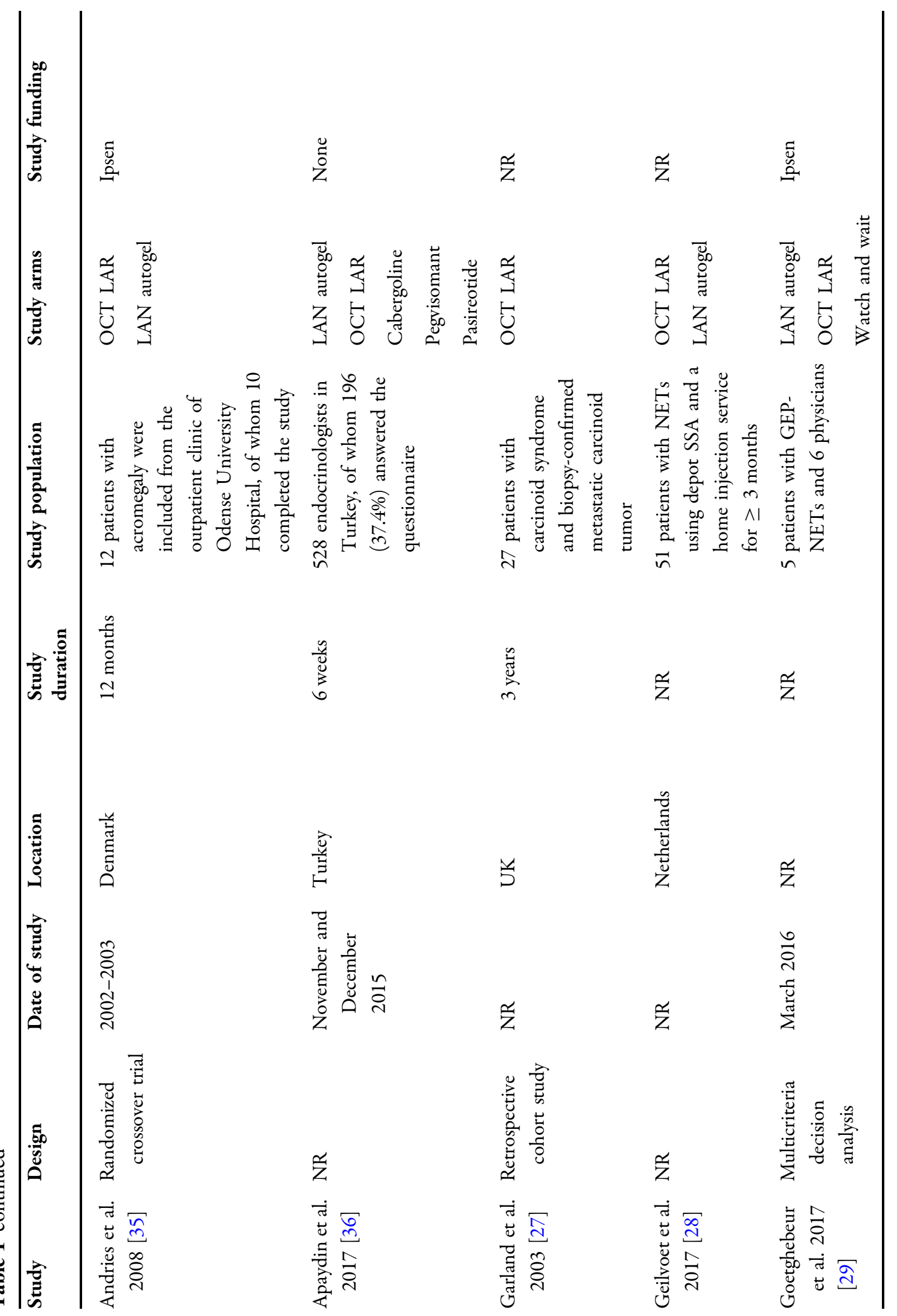




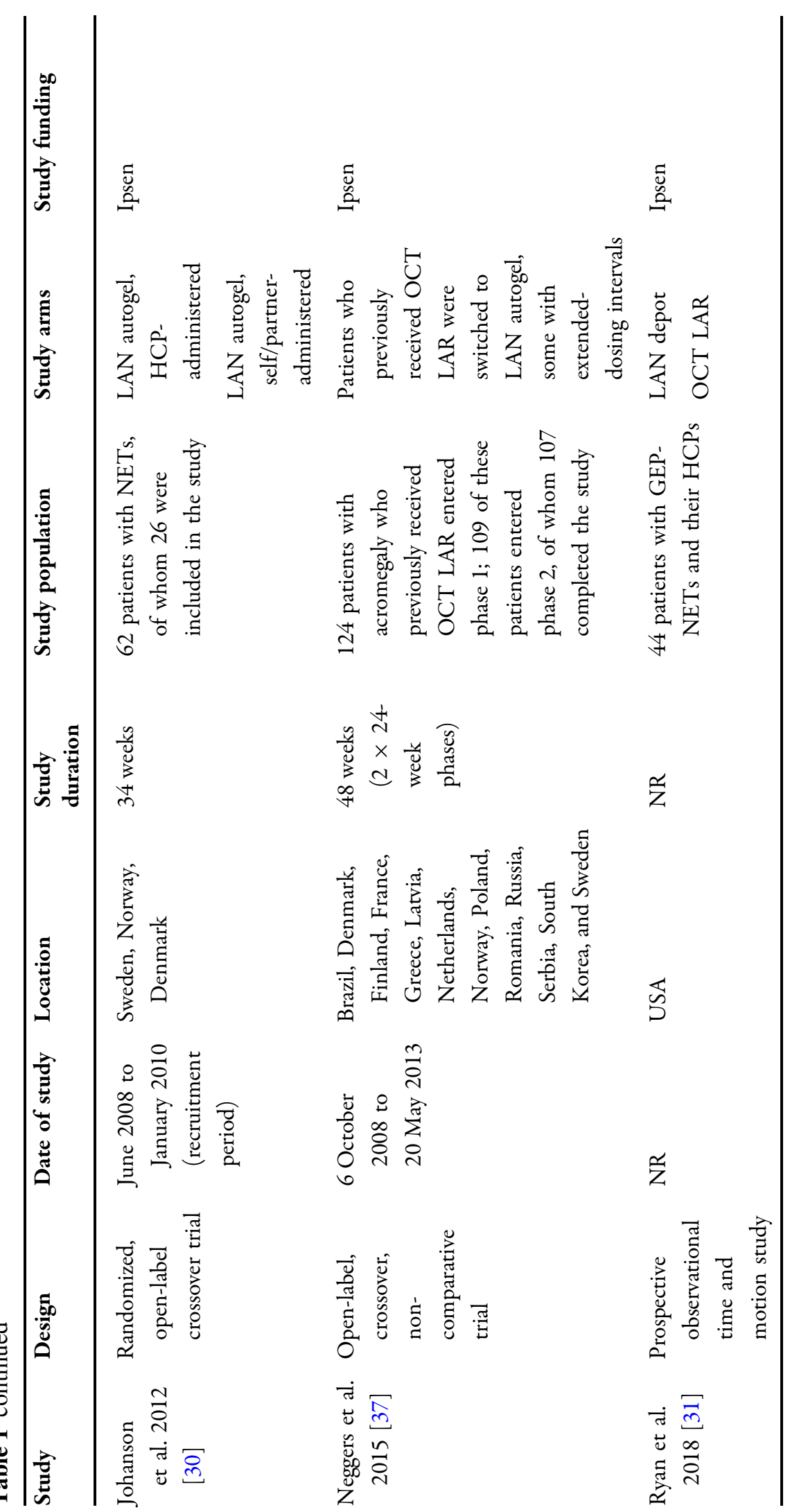




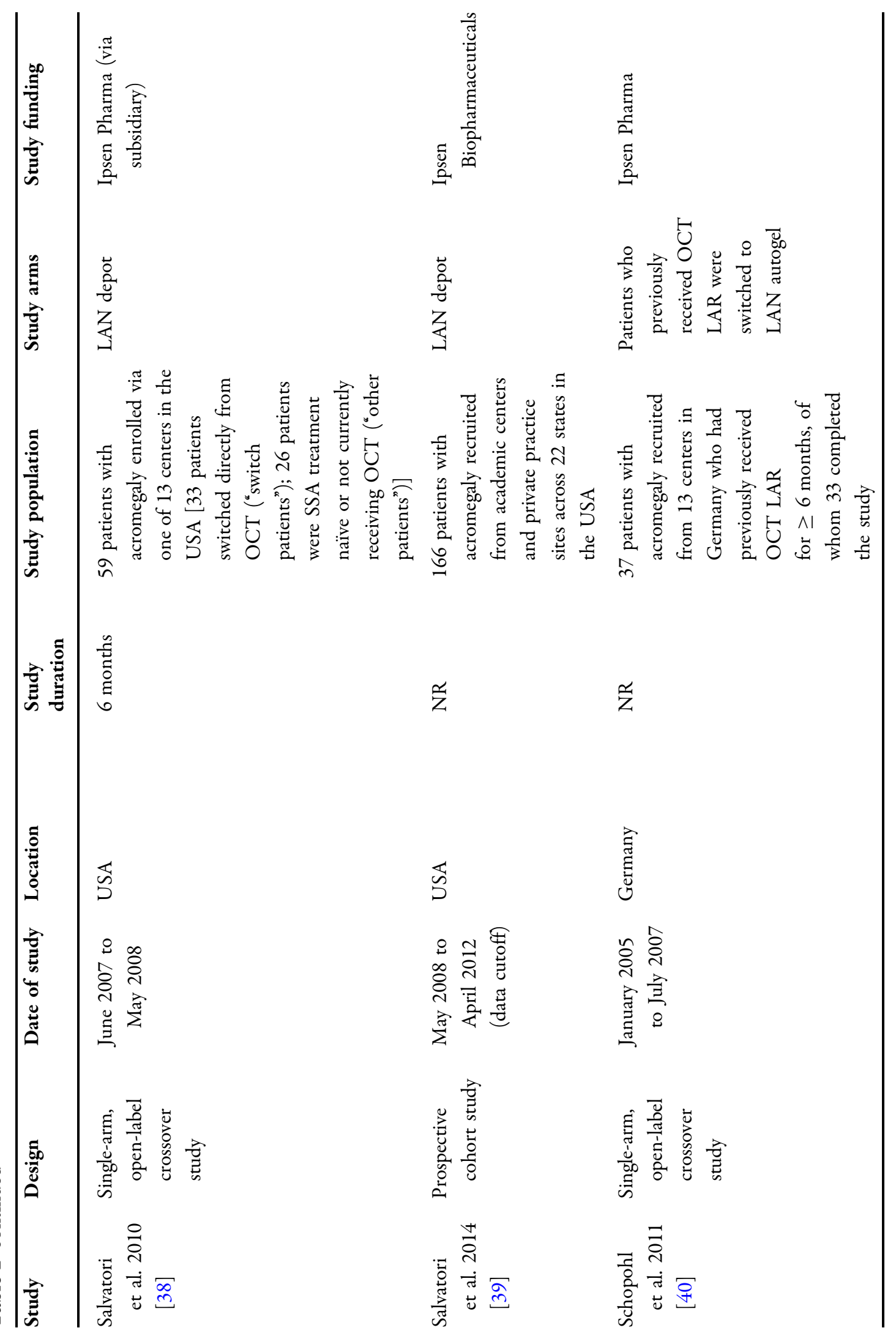




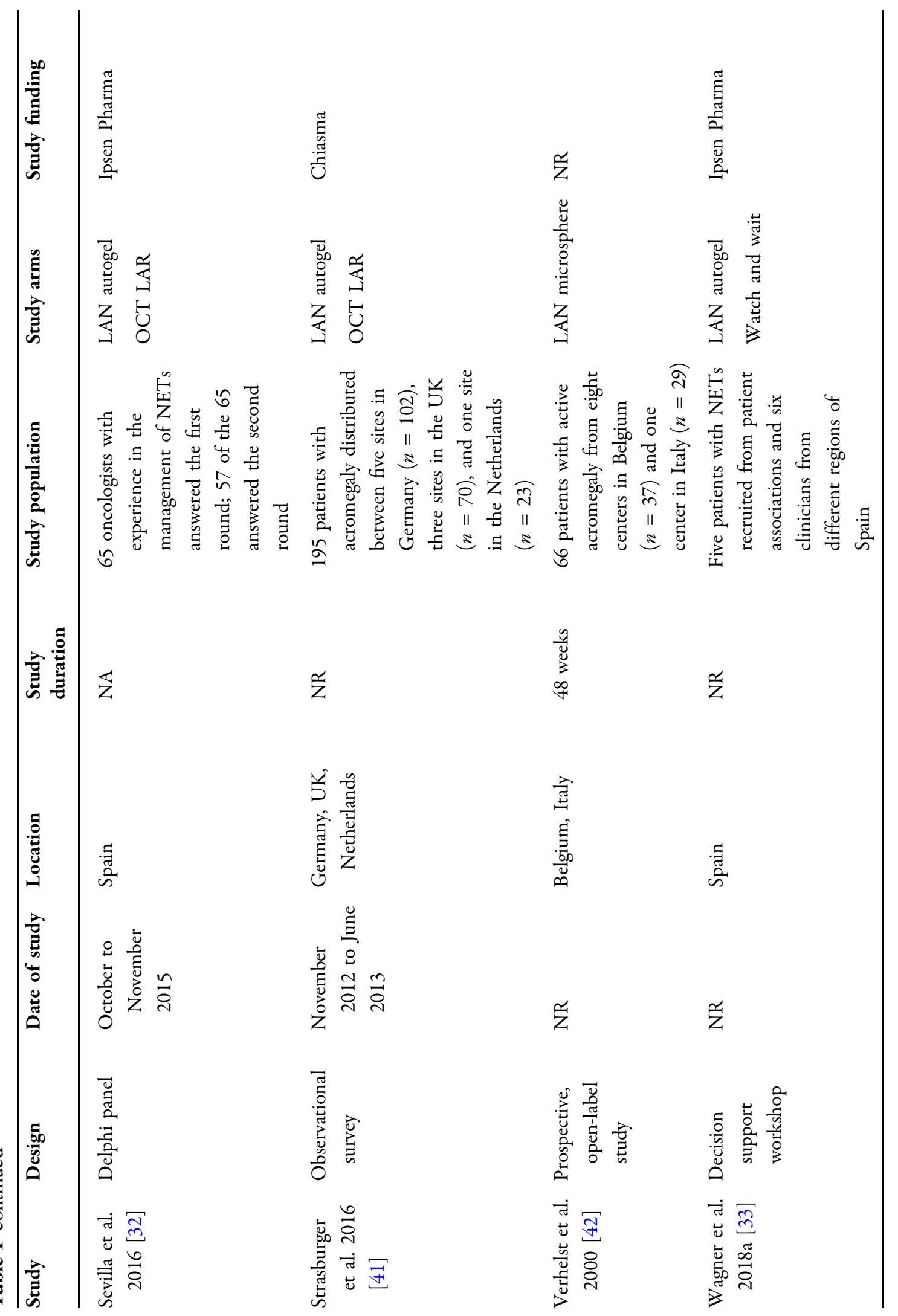




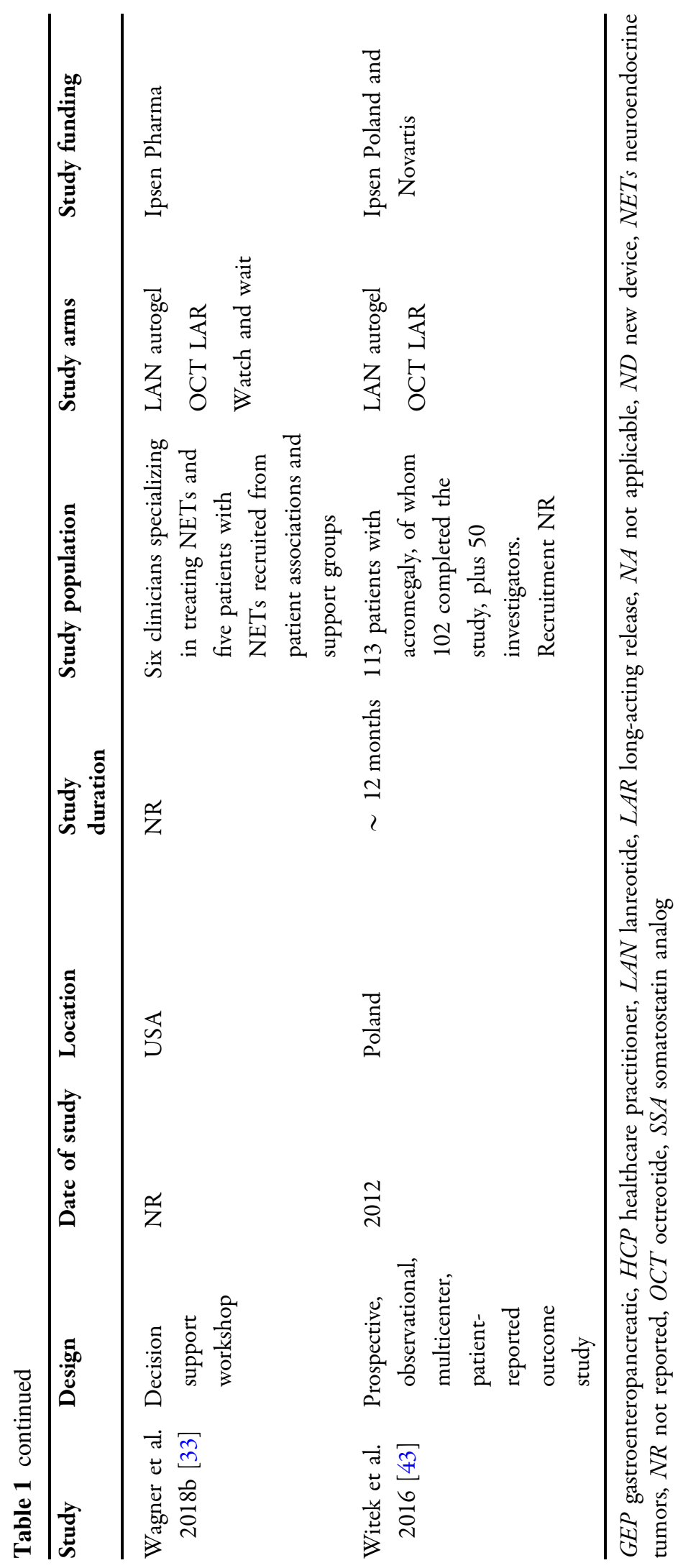


Table 2 Key outcomes relating to patient treatment experience

\begin{tabular}{|c|c|c|c|}
\hline Outcome & Number of studies & $\begin{array}{l}\text { Number of } \\
\text { patients }\end{array}$ & Favored $S A^{b}$ \\
\hline \multirow[t]{2}{*}{ Patient preference } & \multirow[t]{2}{*}{ 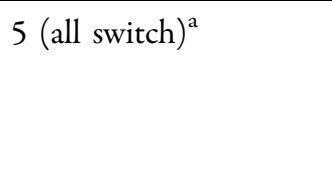 } & \multirow[t]{2}{*}{$10-112$} & $\begin{array}{l}\text { LAN }(\times 4) \\
\quad[34,37,39,40]\end{array}$ \\
\hline & & & OCT LAR $(\times 1)[35]$ \\
\hline $\begin{array}{l}\text { Anxiety/“emotional quality” of } \\
\text { injections }\end{array}$ & 2 (group comparisons) & $119-120$ & $\operatorname{LAN}(\times 2)[25,26]$ \\
\hline Technical problems with injections & $\begin{array}{l}4 \text { (2 switch, } 2 \text { group } \\
\text { comparisons) }\end{array}$ & $25-119$ & $\begin{array}{l}\text { LAN }(\times 4) \\
\quad[26,28,34,43]\end{array}$ \\
\hline \multirow[t]{2}{*}{ Satisfaction/"expectations met" } & \multirow[t]{2}{*}{2 (group comparisons) } & \multirow[t]{2}{*}{$44-102$} & LAN $(\times 1)[43]$ \\
\hline & & & $\mathrm{NP}(\times 1)[31]$ \\
\hline \multirow[t]{2}{*}{ Time associated with injections } & \multirow[t]{2}{*}{2 (group comparisons) } & \multirow[t]{2}{*}{$44-51$} & LAN $(\times 1)[28]$ \\
\hline & & & $\mathrm{NP}(\times 1)[31]$ \\
\hline Injection-associated pain & $\begin{array}{l}3 \text { (2 switch, } 1 \text { group } \\
\text { comparison) }\end{array}$ & $33-195$ & $\operatorname{LAN}(\times 3)[34,38,41]$ \\
\hline Convenience of injections & $\begin{array}{l}2 \text { (1 switch, } 1 \text { group } \\
\text { comparison) }\end{array}$ & $33-119$ & $\operatorname{LAN}(\times 2)[26,38]$ \\
\hline Perceived effectiveness & 1 (switch) & 102 & LAN [43] \\
\hline Indirect costs & 1 (switch) & 26 & LAN [30] \\
\hline
\end{tabular}

$L A N$ lanreotide autogel/depot, $N P$ no preference/favored SSA, OCT LAR octreotide long-acting release, SSA somatostatin analog

${ }^{a}$ Switch refers to studies where patients had direct experience with both LAN and OCT, having switched from one treatment to the other either prior to or during the study

b Aside from preference, the favored SSA was determined by the independent reviewers on the basis of the data included within each study. Where statistical comparisons were performed and found to be non-significant, this was reported as NP; a favored SSA was determined on the basis of numerical comparisons in studies where statistical analyses were not performed

Neggers et al. included three study arms, whereby patients with acromegaly were switched from OCT LAR 4-week dosing interval to LAN with either a 4-week dosing interval or a 6or 8-week extended dosing interval (EDI) [37]. LAN was preferred over OCT LAR in all treatment regimens. At week 48, 53/68 (77.9\%) patients in the 6-week EDI group preferred LAN, vs $10 / 68(14.7 \%)$ who preferred OCT LAR; and 24/26 (92.3\%) patients in the 8-week EDI group preferred LAN, vs $2 / 26$ who preferred the OCT LAR 4-week interval [37]. Although this study sought to investigate the impact of EDIs on treatment preference, notably, 10/13 (76.9\%) patients chose LAN when administered with the same 4-week dosing interval used for their previous OCT LAR treatment; just 2/13 (15.3\%) patients chose OCT LAR and 1/13 (7.7\%) had no preference (reasons for preference were not reported) [37]. Schopohl et al. conducted a similar study in which patients with acromegaly $(n=33)$ switched from OCT LAR with standard dosing interval to LAN with standard dosing interval and EDI groups [40]. Preference for LAN 
Table 3 Treatment specific preference outcomes

\begin{tabular}{|c|c|c|c|c|}
\hline Study & $\begin{array}{l}\text { Indication and } \\
\text { interventions }\end{array}$ & Results & Reasons for preference & $\begin{array}{l}\text { Favored treatment and } \\
\text { respondent experience }\end{array}$ \\
\hline \multicolumn{5}{|c|}{ Statistical Comparisons } \\
\hline \multicolumn{5}{|c|}{ Versus SSA Comparisons } \\
\hline \multicolumn{5}{|c|}{ Patient Perspective } \\
\hline $\begin{array}{l}\text { Salvatori et al } \\
2010^{38}\end{array}$ & $\begin{array}{l}\text { Acromegaly } \\
\text { OCT LAR then LAN } \\
(n=33) \\
\text { (Single-arm, open- } \\
\text { label, } N=59 \text { [n=26 } \\
\text { SSA treatment naïv } \\
\text { or not currently } \\
\text { receiving OCT] })\end{array}$ & $\begin{array}{l}\text { Treatment preference of patients who had switched from } \\
\text { OCT LAR to LAN: } \\
\text { LAN: } 81.3 \% \\
\text { OCT LAR: } 12.5 \%, p=0.0001 \text { LAN vs OCT } \\
6.2 \% \text { of patients had no preference }\end{array}$ & NR & $\begin{array}{l}\text { LAN } \\
\text { Direct experience with both } \\
\text { treatments (within patients) }\end{array}$ \\
\hline \multicolumn{5}{|l|}{ HCP Perspective } \\
\hline $\begin{array}{l}\text { Adelman et al } \\
2012^{44}\end{array}$ & $\begin{array}{l}\text { Acromegaly, GEP- } \\
\text { NETs } \\
\\
\text { Nurses delivered } \\
\text { OCT LAR and LAN } \\
\text { autogel/depot using } \\
\text { an LAN syringe } \\
(\mathrm{N}=77)\end{array}$ & $\begin{array}{l}\text { Attributes were rated on a scale of } 1 \text { (not important at all) to } \\
10 \text { (extremely important), with the option to add additional } \\
\text { attributes, and ranked the } 5 \text { most important from } 1 \text { (most } \\
\text { important) to } 5 \text { (least important). Mean evaluation scores were } \\
\text { calculated for each SSA device attribute. } \\
\text { - Mean evaluation scores were higher for the LAN syringe } \\
\text { than OCT LAR for all } 16 \text { syringe attributes measured } \\
\text { ( } p<0.05 \text { ) except plunger sturdiness } \\
\text { - Overall mean preference scoreb was } 63 \% \text { higher for the } \\
\text { LAN syringe than for OCT LAR: } \\
\text { LAN syringe: } 114 / 160 \\
\text { OCT LAR: } 70 / 160, p \leq 0.01\end{array}$ & $\begin{array}{l}\text { Syringe attributes evaluated: } \\
\text { - Confidence that a full } \\
\text { dose has been delivered } \\
\text { - High product efficacy } \\
\text { - Good safety } \\
\text { - Low risk of clogging } \\
\text { - Easy/convenient } \\
\text { preparation and } \\
\text { injection } \\
\text { - Easy to teach }\end{array}$ & $\begin{array}{l}\text { LAN syringe } \\
\text { Direct experience administering } \\
\text { both treatments (within HCPs) }\end{array}$ \\
\hline & & ${ }^{\mathrm{D} A \text { Attributes weighted by importance to nurses }}$ & 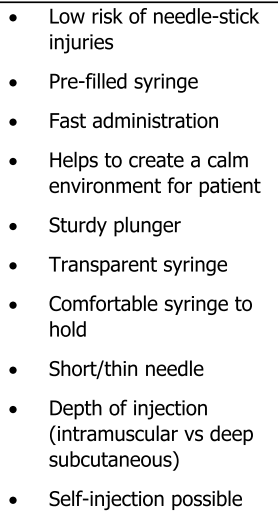 & \\
\hline \multicolumn{5}{|c|}{ Numerical Comparisons } \\
\hline \multicolumn{5}{|c|}{ Versus SSA Comparisons } \\
\hline \multicolumn{5}{|c|}{ Patient Perspective } \\
\hline $\begin{array}{l}\text { Alexopoulou et } \\
\text { al } 2004^{34}\end{array}$ & $\begin{array}{l}\text { Acromegaly } \\
\text { OCT LAR then LAN } \\
\text { autogel }(\mathrm{N}=25)\end{array}$ & $\begin{array}{l}\text { When asked their preference about treatment, } 17 / 25 \text { patients } \\
\text { chose LAN autogel whereas only } 2 / 25 \text { preferred OCT LAR. }\end{array}$ & $\begin{array}{l}\text { Mild-to-moderate pain at the } \\
\text { injection site was reported } \\
\text { by } 76 \% \text { of the patients for } \\
\text { OCT LAR; only } 12 \% \text { of } \\
\text { patients complained of local } \\
\text { pain after the sixth LAN } \\
\text { autogel injection. }\end{array}$ & $\begin{array}{l}\text { LAN autogel } \\
\text { Direct experience on both } \\
\text { treatments (within patients) }\end{array}$ \\
\hline $\begin{array}{l}\text { Andries et al } \\
2008^{35}\end{array}$ & Acromegaly & After the study, four patients chose LAN and six chose OCT. & $\begin{array}{l}\text { Reasons for treatment } \\
\text { choice were based on } \\
\text { administration mode, }\end{array}$ & ОСТ \\
\hline
\end{tabular}


Table 3 continued

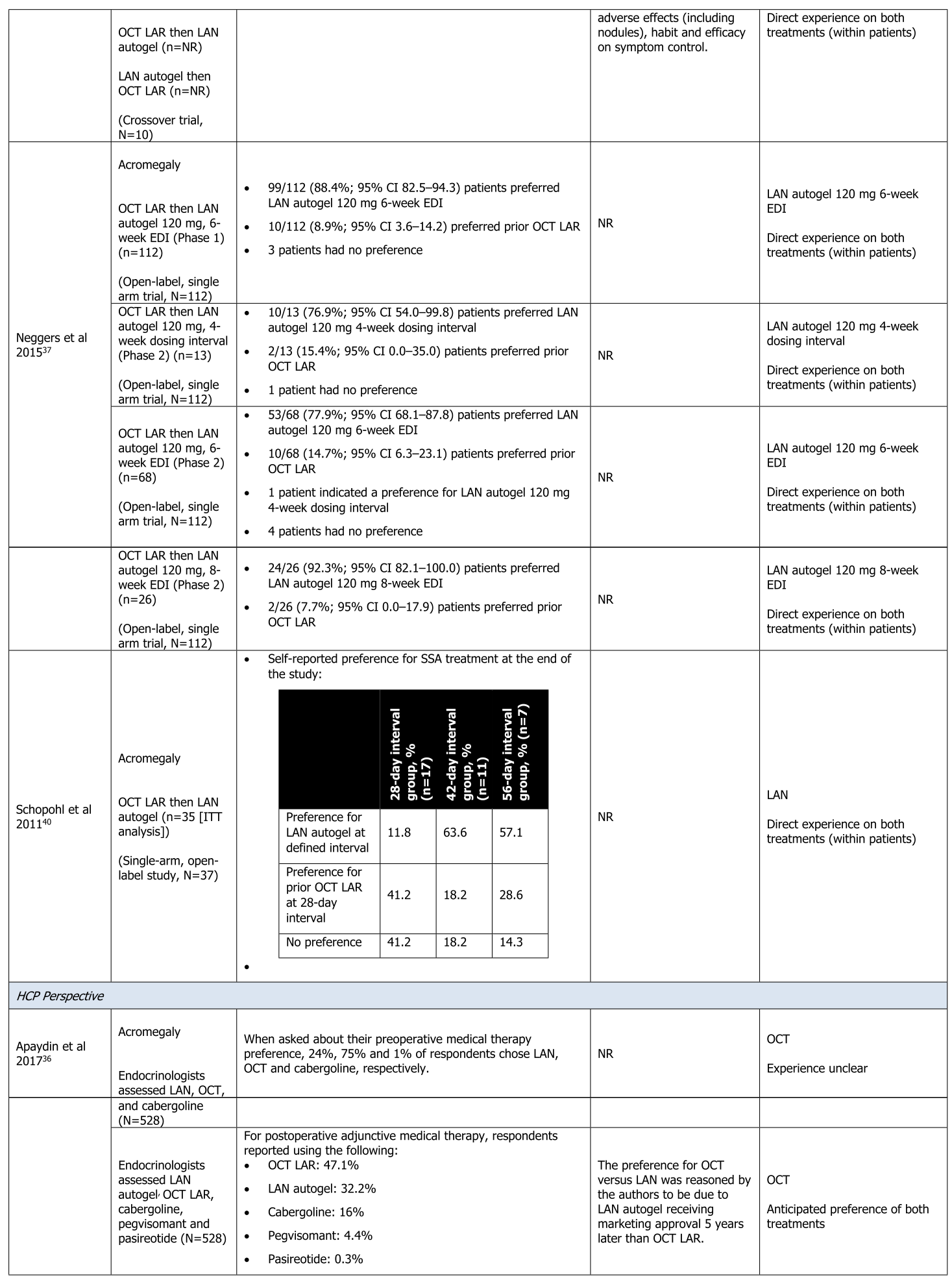

$E D I$ extended dosing interval, GEP gastroenteropancreatic, HCP healthcare practitioner, ITT intention-to-treat, $L A N$ lanreotide, $L A R$ long-acting release, NETs neuroendocrine tumors, $N R$ not reported, $O C T$ octreotide, SSA somatostatin analog 
was higher overall; LAN was preferred in both the 6- and 8-week EDI groups compared with OCT LAR ( $63.6 \%$ vs $18.2 \%$, and $57.1 \%$ vs $28.6 \%$, respectively) [40]. However, preference was higher for OCT LAR over the standard LAN 4 -week dosing interval group (41.2\% vs $11.8 \%)$ [40].

OCT LAR was preferred overall in one crossover study, where $6 / 10$ patients with acromegaly cited fewer adverse effects (such as nodules at the administration site) and greater perceived efficacy compared with LAN [35].

Just two studies specifically reported HCP preferences (Table 3) [36, 44]. A multicenter opinion study in patients with NETs or acromegaly reported HCP preference when HCPs had experience administering both SSAs [44]. LAN was preferred in this study because of the attributes of a LAN injection syringe over OCT LAR, such as faster and smoother administration with lower risk of needle clogging, as well as the option for patients to self-inject using this syringe [44]. Though direct experience with either SSA was unclear, in one study where endocrinologists $(n=196)$ completed an online survey, HCPs reported preference for OCT LAR $(47.1 \% ; n=92)$ over LAN $(32.2 \% ; n=63)$ as their postoperative adjunctive medical therapy of choice, deemed by the study's authors to be based on the longer period of market authorization of OCT LAR compared with LAN, although this varies between continents [36].

\section{Proximal Factors in Treatment Experience}

Outcomes commonly emerging as aspects that influence preference or treatment experience may be divided into proximal and distal factors. Proximal factors refer to the practicalities and immediate aspects of treatment, such as those surrounding method of administration, while distal factors are more conceptual and include emotional aspects of treatment experience, and preference itself.

\section{Injection-Associated Pain}

Injection-associated pain was reported as an outcome in three studies [34, 38, 41], all of which reported LAN as the favored treatment as a result of less injection-associated pain compared with OCT LAR injections. Of 33 patients with acromegaly who switched from OCT LAR to LAN treatment in the Salvatori et al. study, more patients reported that LAN injection was not painful at week 24 vs the OCT injection at week 0 (the final OCT injection prior to switching), compared using a McNemar's test $(50.0 \%$ vs $25.0 \%$ of patients, respectively; $p=0.0201$ ) [38]. Among those who did report pain, patients described the LAN and OCT LAR injections as "somewhat painful" (43.8\% vs $59.4 \% ; p=\mathrm{NR})$, "moderately painful" (6.3\% vs $6.3 \%$; $p=\mathrm{NR})$, or "very painful" $(0.0 \%$ vs $9.4 \%$; $p=\mathrm{NR})[38]$.

One group comparison study found that patients with acromegaly $(n=83$ prescribed LAN; $n=112$ prescribed OCT LAR) considered the overall injection burden to be similar for the two treatments [41]. The authors found small but statistically significant differences in pain and other injection site reactions; OCT LAR injections were associated with slightly greater pain at the injection site hours and days after the injection (hours mean score [scale 0-3], 0.7 vs 0.6 for LAN, $p=0.05$; days mean score [scale $0-3], 0.5$ vs 0.3 for LAN, $p=0.0007$ ). However, LAN injections were associated with the development of nodules, swelling, bruising, and dermatitis (mean score [scale $0-3$ ], 0.8 vs 0.5 for OCT, $p=0.0008$ ) [41]. In one crossover study also in acromegaly, patients reported significantly superior immediate local tolerability at the injection site with LAN injections compared with OCT LAR [34]; 76\% $(n=19)$ of patients reported mild-to-moderate pain at the injection site with OCT LAR, vs $12 \%(n=3)$ reporting local pain after LAN injection.

\section{Technical Problems with Injecting}

Technical problems with injecting, such as needle clogging and difficulty in completing dose administration, were reported as an outcome in four studies [26, 28, 34, 43]. LAN injections were favorable in all four studies, with markedly fewer technical problems reported compared with OCT LAR injections. Alexopoulou et al. reported results from 25 patients with acromegaly who experienced treatment with LAN after switching from OCT LAR [34]. 
Patients informally gave their opinion, with the majority recalling the occurrence of minor or major technical problems for at least one of their six most recent OCT LAR injections, despite injections being administered by experienced paramedical staff $(60 / 150$ injections reported by 19 patients) [34]. By contrast, no technical problems were reported during any LAN injections $(p<0.001)$ [34]. Geilvoet et al. carried out a survey designed for patients with NETs with satisfaction-related theorems with a five-point Likert scale, multiple choice, and free text [28]. The survey revealed that $52 \%$ of patients treated with OCT LAR $(n=23)$ experienced injection problems, compared to $17 \%$ of patients treated with LAN $(n=28)$ [28].

Witek et al. used a crossover study for patients with acromegaly to assess technical problems related to treatment administration [43]. Measured by a visual analog scale (VAS), whereby "no technical problems" was coded as 0 , and "technical problems" was coded as 100 , patients $(n=102)$ reported fewer technical problems related to the administration of LAN (final mean VAS 5.3) compared with OCT LAR (mean VAS 37.6) [43]. Almquist et al. used a survey questionnaire to assess recent SSA injection experiences of patients with GEP-NETs, including technical problems with injecting [26]. Twelve out of 66 (18\%) patients treated with OCT LAR reported problems with their most recent injection, whereas none of the 53 patients receiving LAN treatment reported any problems with their most recent injection $(p=0.001)$ [26]. From the HCP perspective, HCPs in one time and motion study involved with treatment administration indicated concerns over OCT LAR, due to longer time to prepare as well as increased risk of needle clogging $(p=0.034)$ and device failures $(p=0.057)$ [31].

\section{Distal Factors in Treatment Experience}

\section{Anxiety/"Emotional Factors"}

Emotional factors were a notable outcome reported among patients when examining SSA treatment perspectives. Two studies were identified reporting such outcomes, both of which reported group comparisons, with patients experiencing either LAN or OCT LAR treatment; both studies favored LAN $[25,26]$. Adams et al. asked 120 patients to grade the "emotional quality" of their injection experience, where LAN injections were significantly associated with a positive injection experience vs OCT LAR injections $(p<0.001)$ [25]. The questionnaire used by Almquist et al. also assessed levels of anxiety prior to injection [26]. Fewer patients reported moderate-to-high anxiety with LAN injections vs OCT LAR ( $2 \%$ vs $11 \%, n=119$; $p=\mathrm{NR}$ ) [26].

\section{Satisfaction/"Expectations Met"}

One time and motion study reported statistical comparisons for satisfaction between LAN and OCT LAR in terms of treatment delivery attributes from the perspective of both patients and HCPs [31]. Of the 22 patients included for each treatment arm, 20 (90.9\%) patients treated with LAN reported that all or most of their expectations had been met compared with $18(81.8 \%)$ patients treated with OCT LAR $(p=0.25)$ [31]. HCPs involved in preparing and delivering SSAs indicated significantly higher satisfaction with LAN vs OCT LAR (median satisfaction score 5 vs $4, p=0.006)[31]$.

\section{Convenience}

Three studies reported statistical comparisons between LAN and OCT regarding the time taken for treatment administration and patient waiting time in the clinic prior to their injection $[28,31,44]$. Geilvoet et al. concluded from a patient survey that visits by nurses administering LAN $(n=28)$ were significantly shorter than for OCT LAR $(n=23 ; p=0.048)$ [28]. Ryan et al., using a time and motion study comparing treatment delivery attributes between SSAs, reported that patient waiting times (from clinic check-in to check-out) were similar for LAN and OCT LAR. The median total waiting time per visit was $6.2 \mathrm{~min}$ shorter for patients receiving LAN than for those receiving OCT LAR (25.0 $\mathrm{min}$ vs $31.2 \mathrm{~min}$, respectively), though this comparison did not reach statistical significance $(p=0.734 ; n=43)$ [31]. 
From the HCP perspective, Ryan et al. also reported that there was a mean reduction of 3.7 min of treatment delivery time in favor of LAN $(2.5[95 \%$ confidence interval (CI) 2.0-3.1] min) vs OCT LAR $(6.2 \quad[95 \% \quad$ CI 4.4-7.9] $\mathrm{min}, p=0.001$ ) [31]. In an opinion study where syringe attributes were rated by 77 nurses via a questionnaire, Adelman et al. found that injection preparation and administration time were significantly shorter with the LAN syringe than OCT LAR $(p<0.01)$ [44]. This study also reported a significant difference in mean score for ease/convenience of preparation and injection, ranked among the most important attributes by $70 \%$ of nurses, for the LAN syringe (rated 9.4/10) and OCT LAR (rated 3.8/ $10, p<0.05)$ [44]. In another study, comparing HCP-administered injections with LAN vs OCT LAR, LAN injections were judged by the study investigators to be "much easier" or "easier" for $57.1 \%$ of 37 patients, "the same" for $17.1 \%$, "more difficult" for $22.9 \%$, and "much more difficult" for $0.0 \%$ [40]. The most frequently cited reasons for investigator preference for LAN were ease of injection (51.4\%), being time-saving $(45.7 \%)$ and patient preference $(45.7 \%)$ [40].

\section{EDIs}

Four studies reported that patients with acromegaly indicated a greater preference for longer dosing intervals vs shorter intervals $[27,37,40,42]$. In two studies in patients with acromegaly initially treated with OCT LAR (dosing interval of 28 days) who then switched to LAN (42- or 56 -day intervals), over $55 \%$ of patients in both studies expressed a preference for the EDIs of LAN (numerical comparisons only) $[37,40]$. However, one of these studies also reported that a higher proportion of patients demonstrated a preference for a LAN dosing interval of 42 days compared with 56 days $(63.6 \%$ vs $57.1 \%)$, although no statistical comparisons were performed [40]. The preference for the 56-day interval was higher when investigator preference was also taken into account [40]. The remaining two older studies compared short-acting with long-acting formulations; one study included patients switching from daily subcutaneous octreotide injections to monthly intramuscular octreotide
LAR [27], and the other included patients switching from daily subcutaneous octreotide injections to a lanreotide sustained release microsphere formulation, administered by intramuscular injection every 7-14 days [42]. The longer-acting formulations with longer intervals between doses were preferred in both studies [27, 42].

\section{Self-/Partner-Injectable Treatment with LAN}

Self- or partner-injection with LAN was investigated in two studies in patients with acromegaly and one in NETs [30, 38, 39]. Self- or partner-injectable treatment was generally favored compared with attending a medical site or receiving LAN injections administered by HCPs. Johanson et al. reported that reasons pertained to increased independence and convenience, especially for patients living in remote locations. Indirect costs associated with SSA treatments for patients or their caregivers were also estimated on the basis of patient/partner time for travel and injection; one HCP-administered LAN injection was estimated to cost $€ 7.95$, while one self-injection was estimated to cost $€ 0.10$, on account of patients not having to travel or take time off work to be treated [30].

\section{Quality Assessment}

A quality assessment was conducted for each study using the PREFs checklist (Table 4) [24]. Just one of the included studies sufficiently answered all domains of the checklist [44], and six studies answered four out of the five domains [29, 31, 33, 41, 43, 45], most commonly not including statistical comparisons $[29,33,43,45]$. Most of the included studies did not explicitly aim to investigate SSA preference and, as such, purpose in relation to preferences and significance was not a strong domain across studies. Methods of assessment in the context of treatment experience and preferences were reported inconsistently; some studies specifically stated their assessments as part of their methodology, while several did not, or assessment methods were unclear. Statistical comparisons were used to assess differences between 
the SSAs in only $8 / 21$ studies, with the majority of studies making numerical comparisons. A minority of studies explicitly reported preference between SSAs, and the remainder often did not report sufficient information relevant to SSA treatment experience to clearly determine which SSA was favored.

\section{DISCUSSION}

This SLR aimed to identify relevant evidence describing treatment characteristics that impact patient and HCP experience of long-acting, first-generation SSAs in the treatment of NETs or acromegaly. The 21 included studies had varied scopes and used a wide range of quantitative and qualitative designs, leading to considerable heterogeneity across the reported results. Within these studies, factors identified to potentially impact treatment experience included ease of administration and fewer problems with injecting $[26,28,35]$, less pain at the injection site $[34,38]$, and emotional experience, or less anxiety, associated with injecting $[25,26]$. It is perhaps likely that these factors are linked. For example, more problems with injecting may cause pain at the injection site due to re-injection, and more pain could lead to increased anxiety when injecting.

Several factors surrounding mode of administration were identified as contributors to SSA treatment experience, indicating that comfort, convenience, and independence may also be of particular importance in the management of disease and treatment, especially among patients. However, a large proportion of patients who participated in the studies included in this SLR were prescribed LAN at the standard 4-week interval, and their injections were administered by HCPs; notably, three studies reported patient preference for LAN over OCT LAR when patients were receiving HCP injections at the same dosing interval $[34,37,39]$. It is therefore likely that the proximal factors surrounding injections, such as technical problems with injecting and injection-associated pain, are currently greater contributors to patients' treatment experience; when distal factors did not differ between treatment groups, LAN was most commonly preferred or favored. It is interesting to consider that future studies might reveal a shift towards home-based healthcare, especially in the era of the coronavirus disease 2019 (COVID-19) pandemic, and, as such, the option for self- or partner-injection may become a more prominent feature in treatment decision-making. Furthermore, a recent study evaluating patient experience using a LAN syringe introduced in 2019 indicated that use of newer injection devices could further reduce pain and anxiety for patients $[46,47]$.

Where study participants had direct experience of both SSAs, four of the five studies reporting patient preference, and the only study reporting HCP preference, reported preference for LAN over OCT LAR. Among HCPs, preparation and administration of LAN were reported to be quicker and simpler, presenting fewer technical problems such as device clogging, in comparison with OCT LAR [28, 31, 34, 40, 44]. An important caveat of the comparisons made regarding technical problems in the studies included in this SLR is that, since these studies were conducted, a new solvent for OCT LAR reconstitution and a LAN new syringe have become available $[18,19]$. However, in a recent observational study, $4 \%$ of nurses $(n=96)$ reported that purge problems (clogging) persisted when injecting OCT LAR reconstituted with the new solvent [48]. Further, in an international simulated-use study (PRESTO), also completed since this SLR was conducted, most nurses (88/90) expressed a "slight" or "strong" preference for the LAN new syringe vs the OCT LAR syringe (with the latest excipient), citing "confidence the syringe will not be clogged" as the most important attribute [49]. This factor may also impact patients' treatment experience; a recent survey conducted in 2019 found that patients' overall SSA injection experience is also impacted by the training and process knowledge of their HCP, leading to variation in patient satisfaction depending on the nurse administering the SSA [50]. Advancements in device usability and functionality for HCPs may therefore help improve patient satisfaction with injections. 
Table 4 Quality assessment

\begin{tabular}{|c|c|c|c|c|c|}
\hline Study & $\begin{array}{l}\text { Purpose: is the } \\
\text { purpose of the } \\
\text { study in relation } \\
\text { to preferences } \\
\text { clearly stated? }\end{array}$ & $\begin{array}{l}\text { Respondents: } \\
\text { are the } \\
\text { responders } \\
\text { similar to the } \\
\text { non- } \\
\text { responders? }\end{array}$ & $\begin{array}{l}\text { Explanation: are } \\
\text { methods of } \\
\text { assessing } \\
\text { preferences } \\
\text { clearly } \\
\text { explained? }\end{array}$ & $\begin{array}{l}\text { Findings: were all } \\
\text { respondents included in } \\
\text { the reported findings } \\
\text { and analysis of } \\
\text { preference results? }\end{array}$ & $\begin{array}{l}\text { Significance: } \\
\text { were significance } \\
\text { tests used to } \\
\text { assess the } \\
\text { preference } \\
\text { results? }\end{array}$ \\
\hline $\begin{array}{l}\text { Adams et al. } \\
2018 \text { [25] }\end{array}$ & $\mathrm{N}$ & $\mathrm{U}$ & $\mathrm{Y}$ & $\mathrm{Y}$ & Y \\
\hline $\begin{array}{l}\text { Adelman } \\
\text { et al. } 2012 \\
{[44]}\end{array}$ & $\mathrm{Y}$ & $\mathrm{Y}$ & $\mathrm{Y}$ & $\mathrm{Y}$ & Y \\
\hline $\begin{array}{l}\text { Alexopoulou } \\
\text { et al. } 2004 \\
{[34]}\end{array}$ & $\mathrm{N}$ & $\mathrm{Y}$ & $\mathrm{N}$ & $\mathrm{Y}$ & Y \\
\hline $\begin{array}{l}\text { Almquist } \\
\text { et al. } 2017 \\
\text { [26] }\end{array}$ & $\mathrm{N}$ & $\mathrm{Y}$ & $\mathrm{N}$ & $\mathrm{Y}$ & Y \\
\hline $\begin{array}{c}\text { Andries et al. } \\
2008 \text { [35] }\end{array}$ & $\mathrm{N}$ & $\mathrm{Y}$ & $\mathrm{N}$ & $\mathrm{Y}$ & $\mathrm{N}$ \\
\hline $\begin{array}{c}\text { Apaydin et al. } \\
2017 \text { [36] }\end{array}$ & $\mathrm{N}$ & $\mathrm{U}$ & $\mathrm{N}$ & $\mathrm{U}$ & $\mathrm{N}$ \\
\hline $\begin{array}{c}\text { Garland et al. } \\
2003 \text { [27] }\end{array}$ & $\mathrm{N}$ & $\mathrm{U}$ & $\mathrm{N}$ & $\mathrm{U}$ & $\mathrm{N}$ \\
\hline $\begin{array}{c}\text { Geilvoet et al. } \\
2017 \text { [28] }\end{array}$ & $\mathrm{N}$ & $\mathrm{U}$ & $\mathrm{N}$ & $\mathrm{U}$ & Y \\
\hline $\begin{array}{l}\text { Goetghebeur } \\
\text { et al. } 2017 \\
{[29]}\end{array}$ & $\mathrm{Y}$ & $\mathrm{Y}$ & $\mathrm{Y}$ & $\mathrm{Y}$ & $\mathrm{N}$ \\
\hline $\begin{array}{l}\text { Johanson } \\
\text { et al. } 2012 \\
\text { [30] }\end{array}$ & $\mathrm{Y}$ & $\mathrm{U}$ & $\mathrm{Y}$ & $\mathrm{N}$ & $\mathrm{N}$ \\
\hline $\begin{array}{l}\text { Neggers et al. } \\
2015 \text { [37] }\end{array}$ & $\mathrm{N}$ & $\mathrm{U}$ & $\mathrm{N}$ & $\mathrm{N}$ & $\mathrm{N}$ \\
\hline $\begin{array}{l}\text { Ryan et al. } \\
2018 \text { [31] }\end{array}$ & $\mathrm{Y}$ & $\mathrm{Y}$ & $\mathrm{N}$ & $\mathrm{Y}$ & Y \\
\hline $\begin{array}{l}\text { Salvatori } \\
\text { et al. } 2010 \\
\text { [38] }\end{array}$ & $\mathrm{N}$ & $\mathrm{U}$ & $\mathrm{N}$ & $\mathrm{Y}$ & Y \\
\hline
\end{tabular}


Table 4 continued

\begin{tabular}{|c|c|c|c|c|c|}
\hline Study & $\begin{array}{l}\text { Purpose: is the } \\
\text { purpose of the } \\
\text { study in relation } \\
\text { to preferences } \\
\text { clearly stated? }\end{array}$ & $\begin{array}{l}\text { Respondents: } \\
\text { are the } \\
\text { responders } \\
\text { similar to the } \\
\text { non- } \\
\text { responders? }\end{array}$ & $\begin{array}{l}\text { Explanation: are } \\
\text { methods of } \\
\text { assessing } \\
\text { preferences } \\
\text { clearly } \\
\text { explained? }\end{array}$ & $\begin{array}{l}\text { Findings: were all } \\
\text { respondents included in } \\
\text { the reported findings } \\
\text { and analysis of } \\
\text { preference results? }\end{array}$ & $\begin{array}{l}\text { Significance: } \\
\text { were significance } \\
\text { tests used to } \\
\text { assess the } \\
\text { preference } \\
\text { results? }\end{array}$ \\
\hline $\begin{array}{l}\text { Salvatori } \\
\qquad \text { et al. } 2014 \\
\text { [39] }\end{array}$ & $\mathrm{N}$ & Y & Y & Y & $\mathrm{N}$ \\
\hline $\begin{array}{l}\text { Schopohl } \\
\text { et al. } 2011 \\
{[40]}\end{array}$ & $\mathrm{N}$ & $\mathrm{U}$ & Y & $\mathrm{Y}$ & $\mathrm{N}$ \\
\hline $\begin{array}{r}\text { Sevilla et al. } \\
2016 \text { [32] }\end{array}$ & $\mathrm{N}$ & Y & Y & Y & $\mathrm{N}$ \\
\hline $\begin{array}{l}\text { Strasburger } \\
\text { et al. } 2016 \\
{[41]}\end{array}$ & $\mathrm{N}$ & Y & Y & Y & Y \\
\hline $\begin{array}{l}\text { Verhelst et al. } \\
2000[42]\end{array}$ & $\mathrm{N}$ & $\mathrm{U}$ & $\mathrm{N}$ & $\mathrm{U}$ & $\mathrm{N}$ \\
\hline $\begin{array}{l}\text { Wagner et al. } \\
\text { 2018a [33] }\end{array}$ & $\mathrm{Y}$ & $\mathrm{Y}$ & Y & Y & $\mathrm{N}$ \\
\hline $\begin{array}{l}\text { Wagner et al. } \\
2018 b \text { [33] }\end{array}$ & $\mathrm{Y}$ & Y & Y & Y & $\mathrm{N}$ \\
\hline $\begin{array}{l}\text { Witek et al. } \\
2016 \text { [43] }\end{array}$ & $\mathrm{Y}$ & Y & Y & Y & $\mathrm{N}$ \\
\hline
\end{tabular}

$N$ no, $U$ unable to determine, $Y$ yes

Habit, effectiveness, and adverse effects of LAN were found to contribute to patient preference for OCT LAR in one study [35]. Although experience with LAN was unclear, HCPs reported preference for OCT LAR in a study conducted in 2017, based on a longer period of market authorization compared with LAN [36]. Overall, however, perceived efficacy was not one of the main factors contributing to patient or HCP preference in the majority of studies. This finding aligns with previously reported data indicating that the efficacy of the two SSAs may be comparable in both acromegaly and NETs $[40,51,52]$, or other factors beyond treatment efficacy, such as technical problems when administering treatment and injection- associated pain, may be more important to patients' overall treatment experience.

Several limitations within the captured studies and SLR methodology should be considered when interpreting the results. In terms of the assessment tools used in the identified studies, there was a lack of standardization across the included studies, and none employed validated quality of life or utility measures, limiting the conclusions that can be drawn from any comparisons made. Although nine studies did include statistical analyses, some of these may not have used robust statistical methods to ascertain significant differences, and differences may not necessarily be clinically significant in certain instances, despite 
statistical significance. Additionally, for several of the outcomes assessed, including pain, anxiety, and nodules, there was a lack of information to clarify the relative burden of those factors for patients. When assessing different interventions experienced by the same patient, recall of the first treatment is subject to bias. This may be important when considering that patients switched in the direction of OCT LAR to LAN in all crossover studies and were not blinded to the treatment received. This possible bias would not be a concern in the 11 studies with treatment arms running in parallel.

While seven of the studies included in this SLR reported preference as an outcome, none of the included studies specifically aimed to assess patient/HCP preference. For the purpose of this SLR, favored treatment among patients or HCPs in a number of studies was inferred through statistical significance or numerical comparisons of data on factors such as treatment preparation and administration time, visit times, technical problems, and side effects. Although such factors are advantageous and may drive preference, they are not necessarily correlated with patient/HCP preference for one intervention over another and, as such, should be interpreted with caution. The SLR search strategy excluded non-English-language full texts, potentially restricting the identification of all relevant evidence and limiting the global relevance of the review findings; the included studies were conducted in Western countries and the conclusions of this SLR may not be applicable for patients in Asian countries and other global regions. Finally, as is to be expected, the manufacturers of the two SSAs have sponsored much of the research identified in our review. Truly independent research into patient preferences is difficult to obtain.

\section{CONCLUSIONS}

This SLR has identified a moderate volume of evidence describing the treatment perspectives of patients with acromegaly and NETs, as well as their HCPs. While highlighting the heterogeneity in the way that treatment preferences have previously been reported, a number of common outcomes underlying treatment experience, including injection-associated pain, emotional quality of injections, time and convenience of treatment administration, and patient independence and autonomy, were identified. Future research should be specifically designed to assess patient preference and to determine which factors contribute the most to positive patient and HCP experience. Studies should also utilize a common framework or validated reporting instrument to allow outcomes reported across studies to be pooled and analyzed more robustly. The findings of this SLR provide a basis that could be used to inform development of decision-making criteria, considering the patient perspective when initiating long-acting SSA treatment.

\section{ACKNOWLEDGEMENTS}

The authors thank Daphne T. Adelman for her contributions to the analysis and interpretation of the data and critically revising drafts for important intellectual content.

Funding. This study was sponsored by Ipsen. The study sponsor is also funding the journal's Rapid Service and Open Access Fees.

Medical Writing and Editorial Assistance. The authors thank Oliver Palmer, BSc (Hons), and Amelia Frizell-Armitage, PhD, of Costello Medical, UK, for medical writing and editorial support, which was sponsored by Ipsen in accordance with Good Publication Practice guidelines.

Authorship. All named authors meet the International Committee of Medical Journal Editors (ICMJE) criteria for authorship for this article, take responsibility for the integrity of the work as a whole, and have given their approval for this version to be published.

Authorship Contributions. Substantial contributions to study conception and design: DC, JE, MF, SN, DVG, JH, MSK; substantial contributions to analysis and interpretation of the 
data: DC, JE, MF, SN, DVG, JH, MSK; drafting the article or revising it critically for important intellectual content: DC, JE, MF, SN, DVG, JH, MSK; final approval of the version of the article to be published: DC, JE, MF, SN, DVG, JH, MSK.

Prior Presentation. This manuscript is based on work that has been previously presented at the 17th Annual ENETS Conference for the Diagnosis and Treatment of Neuroendocrine Tumor Disease, in Barcelona, Spain, on March 11-13, 2020.

Disclosures. DC received research grants and consulting honoraria from Ipsen and Novartis.

DVG is Vice-President of the Belgian NET and MEN Association and board member of INCA. Both organizations receive grants from Ipsen and Novartis. No personal fees or renumeration have been received.

JE has nothing to disclose.

$\mathrm{JH}$ is the President of CNETS. The organization receives grants annually from Ipsen and Novartis. JH personally received one small honorarium from Novartis.

MF was an employee of Ipsen at the time of these analyses. MF is now an employee of Bayer Pharmaceuticals.

MSK received consulting honoraria and speaker fees from Ipsen and Novartis.

SN received speaker/consultancy fees from Pfizer and Ipsen, and research grants from Pfizer.

Compliance with Ethics Guidelines. This article is based on previously conducted studies and does not contain any new studies with human participants or animals performed by any of the authors.

Data Availability. Data sharing is not applicable to this article as no datasets were generated or analyzed during the current study. All data included in this manuscript have been reported in published studies.

Open Access. This article is licensed under a Creative Commons Attribution-NonCommercial 4.0 International License, which permits any non-commercial use, sharing, adaptation, distribution and reproduction in any medium or format, as long as you give appropriate credit to the original author(s) and the source, provide a link to the Creative Commons licence, and indicate if changes were made. The images or other third party material in this article are included in the article's Creative Commons licence, unless indicated otherwise in a credit line to the material. If material is not included in the article's Creative Commons licence and your intended use is not permitted by statutory regulation or exceeds the permitted use, you will need to obtain permission directly from the copyright holder. To view a copy of this licence, visit http://creativecommons.org/licenses/by$\mathrm{nc} / 4.0 /$.

\section{REFERENCES}

1. Delle Fave G, O'Toole D, Sundin A, et al. ENETS consensus guidelines update for gastroduodenal neuroendocrine neoplasms. Neuroendocrinology. 2016;103:119-24.

2. Matfin G. Endocrine and metabolic medical emergencies: a clinician's guide. New York: Wiley; 2018.

3. Dimitriadis GK, Weickert MO, Randeva HS, et al. Medical management of secretory syndromes related to gastroenteropancreatic neuroendocrine tumours. Endocr Relat Cancer. 2016;23:R423.

4. Pavel M, O'Toole D, Costa F, et al. ENETS consensus guidelines update for the management of distant metastatic disease of intestinal, pancreatic, bronchial neuroendocrine neoplasms (NEN) and NEN of unknown primary site. Neuroendocrinology. 2016;103:172-85.

5. Shah MH. J Natl Compr Canc Netw (2019). http:// www.nccn.org/professionals/physician_gls/pdf/ neuroendocrine.pdf. Accessed 22 Dec 2020.

6. Katznelson L, Laws ER Jr, Melmed S, et al. Acromegaly: an Endocrine Society clinical practice guideline. J Clin Endocrinol Metab. 2014;99: 3933-51.

7. Brue T, Castinetti F. The risks of overlooking the diagnosis of secreting pituitary adenomas. Orphanet J Rare Dis. 2016;11:135-135. 
8. Somatuline Autogel. Summary of product characteristics (2018). https://www.medicines.org.uk/ emc/product/8258/smpc. Accessed 22 Dec 2020.

9. Ezzat S, Snyder PJ, Young WF, et al. Octreotide treatment of acromegaly. A randomized, multicenter study. Ann Intern Med. 1992;117:711-8.

10. Lombardi G, Minuto F, Tamburrano G, et al. Efficacy of the new long-acting formulation of lanreotide (lanreotide autogel) in somatostatin analogue-naive patients with acromegaly. J Endocrinol Investig. 2009;32:202-9.

11. Melmed S, Popovic V, Bidlingmaier M, et al. Safety and efficacy of oral octreotide in acromegaly: results of a multicenter phase III trial. J Clin Endocrinol Metab. 2015;100:1699-708.

12. Newman CB, Melmed S, Snyder PJ, et al. Safety and efficacy of long-term octreotide therapy of acromegaly: results of a multicenter trial in 103 patients-a clinical research center study. J Clin Endocrinol Metab. 1995;80:2768-75.

13. Shimatsu A, Teramoto A, Hizuka N, et al. Efficacy, safety, and pharmacokinetics of sustained-release lanreotide (lanreotide autogel) in Japanese patients with acromegaly or pituitary gigantism. Endocr J. 2013;60:651-63.

14. Caplin ME, Pavel M, Ćwikła JB, et al. Lanreotide in metastatic enteropancreatic neuroendocrine tumors. NEJM. 2014;371:224-33.

15. Lau SC, Abdel-Rahman O, Cheung WY. Improved survival with higher doses of octreotide long-acting release in gastroenteropancreatic neuroendocrine tumors. Med Oncol. 2018;35:123.

16. Rinke A, Müller HH, Schade-Brittinger C, et al. Placebo-controlled, double-blind, prospective, randomized study on the effect of octreotide LAR in the control of tumor growth in patients with metastatic neuroendocrine midgut tumors: a report from the PROMID Study Group. J Clin Oncol. 2009;27:4656-63.

17. Wymenga AN, Eriksson B, Salmela PI, et al. Efficacy and safety of prolonged-release lanreotide in patients with gastrointestinal neuroendocrine tumors and hormone-related symptoms. J Clin Oncol. 1999;17:1111.

18. Somatuline Depot (lanreotide) injection prescribing information (2019). https://www.accessdata.fda. gov/drugsatfda_docs/label/2019/022074s024lbl. pdf. Accessed 4 Jan 2021.

19. Sandostatin LAR Depot prescribing information (2019). https://www.accessdata.fda.gov/drugsatfda_ docs/label/2019/021008s043lbl.pdf. Accessed 4 Jan 2021.

20. Troconiz IF, Cendros JM, Peraire C, et al. Population pharmacokinetic analysis of lanreotide autogel in healthy subjects: evidence for injection interval of up to 2 months. Clin Pharmacokinet. 2009;48: 51-62.

21. Valery C, Paternostre M, Robert B, et al. Biomimetic organization: octapeptide self-assembly into nanotubes of viral capsid-like dimension. Proc Natl Acad Sci USA. 2003;100:10258-62.

22. Sandostatin LAR. Summary of product characteristics (2018). https://www.medicines.org.uk/emc/ product/1038/smpc. Accessed 4 Jan 2021.

23. EMC. Octreotide 100 micrograms $/ 1 \mathrm{ml}$ solution for injection SmPC (2019). https://www.medicines.org. uk/emc/product/373/smpc. Accessed 4 Jan 2021.

24. Joy SM, Little E, Maruthur NM, et al. Patient preferences for the treatment of type 2 diabetes: a scoping review. Pharmacoeconomics. 2013;31: 877-92.

25. Adams J, Ray D, Willmon R, et al. Living with neuroendocrine tumors: assessing quality of life (QoL) through a mobile application. J Clin Oncol. 2018;36. https://doi.org/10.1200/JCO.2018.36.4_ suppl.359.

26. Almquist M, Myrenfors P, Strom T, et al. STREETsomatostatin treatment experience trial. Neuroendocrinology. 2017;105(Suppl 1):191.

27. Garland J, Buscombe JR, Bouvier C, et al. Sandostatin LAR (long-acting octreotide acetate) for malignant carcinoid syndrome: a 3-year experience. Aliment Pharmacol Ther. 2003;17:437-44.

28. Geilvoet W, Feelders R, De Herder WW. Patient satisfaction regarding home injection service for somatostatin analogues: a survey among patients with a neuroendocrine tumour. Neuroendocrinology. 2017;105(Suppl 1):198.

29. Goetghebeur M, Samaha D, Khoury H, et al. To treat or watch? Identifying drivers of decisions for patients with GEP-NET using reflective multi-criteria decision analysis. Neuroendocrinology. 2017;105(Suppl 1):235.

30. Johanson V, Wilson B, Abrahamsson A, et al. Randomized crossover study in patients with neuroendocrine tumors to assess patient preference for lanreotide autogel given by either self/partner or a health care professional. Patient Prefer Adherence. 2012;6:703-10. 
31. Ryan P, McBride A, Ray D, et al. Lanreotide depot/ autogel vs. octreotide LAR for patients with advanced gastroenteropancreatic neuroendocrine tumours: an observational time and motion analysis. In: NANETS 11th annual multidisciplinary NET symposium, 04-06 Oct 2018, Seattle, WA, USA. 2018;P-12:211-2. https://nanets.net/abstractsarchive/2018/948-abstract-p12/file. Accessed 4 Jan 2021.

32. Sevilla I, Segura A, Capdevila J, et al. Management of controversial gastroenteropancreatic neuroendocrine tumour clinical situations with somatostatin analogues: results of a Delphi questionnaire panel from the NETPraxis program. BMC Cancer. 2016;16:858.

33. Wagner M, Samaha D, Cuervo J, et al. Applying reflective multicriteria decision analysis (MCDA) to patient-clinician shared decision-making on the management of gastroenteropancreatic neuroendocrine tumors (GEP-NET) in the Spanish context. Adv Ther. 2018;35:1215-31.

34. Alexopoulou O, Abrams P, Verhelst J, et al. Efficacy and tolerability of lanreotide autogel therapy in acromegalic patients previously treated with octreotide LAR. Eur J Endocrinol. 2004;151:317-24.

35. Andries M, Glintborg D, Kvistborg A, et al. A 12-month randomized crossover study on the effects of lanreotide autogel and octreotide longacting repeatable on GH and IGF-l in patients with acromegaly. Clin Endocrinol. 2008;68:473-80.

36. Apaydin T, Ozkaya HM, Keskin FE, et al. Daily life reflections of acromegaly guidelines. J Endocrinol Investig. 2017;40:323-30.

37. Neggers SJ, Pronin V, Balcere I, et al. Lanreotide autogel $120 \mathrm{mg}$ at extended dosing intervals in patients with acromegaly biochemically controlled with octreotide LAR: The LEAD study. Eur J Endocrinol. 2015;173:313-23.

38. Salvatori R, Nachtigall LB, Cook DM, et al. Effectiveness of self- or partner-administration of an extended-release aqueous-gel formulation of lanreotide in lanreotide-naive patients with acromegaly. Pituitary. 2010;13:115-22.

39. Salvatori R, Woodmansee WW, Molitch M, et al. Lanreotide extended-release aqueous-gel formulation, injected by patient, partner or healthcare provider in patients with acromegaly in the United States: 1-year data from the SODA registry. Pituitary. 2014;17:13-21.

40. Schopohl J, Strasburger CJ, Caird D, et al. Efficacy and acceptability of lanreotide autogel $120 \mathrm{mg}$ at different dose intervals in patients with acromegaly previously treated with octreotide LAR. Exp Clin Endocrinol Diabetes. 2011;119:156-62.

41. Strasburger CJ, Karavitaki N, Stormann S, et al. Patient-reported outcomes of parenteral somatostatin analogue injections in 195 patients with acromegaly. Eur J Endocrinol. 2016;174:355-62.

42. Verhelst JA, Pedroncelli AM, Abs R, et al. Slow-release lanreotide in the treatment of acromegaly: a study in 66 patients. Eur J Endocrinol. 2000;143: 577-84.

43. Witek P, Mucha S, Ruchala M. Patient satisfaction and preferences of lanreotide autogel treatment in acromegaly. Endokrynologia Polska. 2016;67: 572-9.

44. Adelman DT, Burgess A, Davies PR. Evaluation of long-acting somatostatin analog injection devices by nurses: a quantitative study. Med Devices (Auckl). 2012;5:103-9.

45. Wagner M, Samaha D, Khoury H, et al. Development of a framework based on reflective MCDA to support patient-clinician shared decision-making: the case of the management of gastroenteropancreatic neuroendocrine tumors (GEP-NET) in the United States. Adv Ther. 2018;35:81-99.

46. Adelman DT, Van Genechten D, Megret CM, et al. Co-creation of a lanreotide autogel/depot syringe for the treatment of acromegaly and neuroendocrine tumours through collaborative human factor studies. Adv Ther. 2019;36:3409-23.

47. Walter T, Eskenazi M, Rama N, et al. Patient and nurse satisfaction with the new lanreotide autogel pre-filled syringe in neuroendocrine tumors (NET): a prospective study (SONATE). In: ENETS 17th annual conference, 11-13 Mar 2020, Barcelona, Spain. 2020;2824. https://www.enets.org/patientand-nurse-satisfaction-with-the-new-lanreotide-auto gel-prefilled-syringe-in-neuroendocrine-tumors-neta-prospective-study-sonate.html. Accessed 4 Jan 2021.

48. Cadiot G, Coriat R, Raverot G, et al. EvAluation de Satisfaction Infirmière (Nurse satisfaction evaluation). Observational study of the preparation and intramuscular administration of the previous and new long-acting release octreotide LAR formulation (EASI). In: ENETS 17th annual conference, 11-13 Mar 2020, Barcelona, Spain. 2020;2802. https:// www.enets.org/evaluation-de-satisfaction-infirmierenurse-satisfaction-evaluationobservational-studyof-the-preparation-and-intramuscular-administrationof-the-previousand-new-long-acting-release-octreo tide-lar-formulation-easi.html. Accessed 4 Jan 2021.

49. Adelman DT, Truong-Thanh X, Feuilly M, et al. Evaluation of nurse preferences between the 
lanreotide autogel new syringe and the octreotide long-acting release syringe: an international simulated-use study (PRESTO). Adv Ther. 2020;37: 1608-19.

50. Darden C, Ray D, Goldstein G, et al. Satisfaction survey of administration modes for long-acting somatostatin analog therapy in patients with neuroendocrine tumors. In: NANETS 12th annual multidisciplinary NET symposium, 03-05 Oct 2019, Boston, MA, USA. 2019;P-3:181-2. https://nanets. net/abstracts-archive/2019/1328-p3-satisfactionsurvey-ofadministration-modes-for-long-acting-lasomatostatin-analog-ssa-therapy-in-patients- withneuroendocrine-tumors-nets/file. Accessed 4 Jan 2021.

51. Tutuncu Y, Berker D, Isik S, et al. Comparison of octreotide LAR and lanreotide autogel as post-operative medical treatment in acromegaly. Pituitary. 2012;15:398-404.

52. Thiel SW, Romijn JA, Biermasz NR, et al. Octreotide long-acting repeatable and lanreotide autogel are equally effective in controlling growth hormone secretion in acromegalic patients. Eur J Endocrinol. 2004;150:489-95. 